\title{
AVALIAÇÃO QUÍMICA E NUTRICIONAL DO QUEIJO MOZZARELLA E IOGURTE DE LEITE DE BÚFALA
}

\author{
M.R. VERRUMA; A.J. de OLIVEIRA \\ Departamento de Ciencia e Tecnologia Agroindustrial - ESALQ/USP, C.P. 9, CEP: 13418-900-Piracicaba,SP. \\ J.M. SALGADO \\ Departamento de Economia Domésticas - ESALQ/USP, C.P. 9, CEP:13418-900-Piracicaba,SP.
}

RESUMO: O presente trabalho teve por objetivo verificar a composiçāo química e nutricional do queijo e iogurte elaborados com leite de búfala e comparados com aqueles elaborados com leite de vaca. Dos resultados obtidos foram obtidas as seguintes conclusões: o queijo tipo mozzarella e o iogurte elaborado com leite de búfala apresentaram níveis superiores em proténa, gordura, cinzas, cálcio e fósforo, estando relacionados com a composição química inicial do leite. Os níveis de digestibilidade in viro dos queijos tipo mozzarella e iogurte de leite de búfala apresentaram resultados semelhantes aos elaborados com leite de vaca, indicando níveis adequados de digestibilidade para consumo humano.

Descritores: leite de búfala, queijo, iogurte, digestibilidade in vitro

\section{CHEMICAL AND NUTRITIONAL EVALUATION OF MOZZARELLA CHEESE AND YOGURT MADE FROM BUFFALO MILK}

\begin{abstract}
AESTRACT: The chemical and nutritional compositions of cheese and yogurt made from buffalo and cow milk were compared. The following conclusions were obtained: mozzarella type cheese and yogurt made from buffalo milk exhibited higher content of protein, fat, minerals, calcium and phosphorus when compared to those made from cow milk; in vitro digestibility tests of mozzarella type cheese and yogurt made from buffalo milk were similar to those of cow milk, indicantig suitable digestibility levels for human consumption.
\end{abstract}

Key Words: buffalo milk, cheese, yogurt, digestibility in vitro

\section{INTRODUÇÃO}

Nos últimos 10 anos houve um aumento considerável na população de búfalos no Brasil, chegando a um total de 2.000 .000 cabeças, representando cerca de $1,5 \%$ do rebanho nacional (FAO, 1991), com uma previsão de aumento de população em $12,7 \%$ ao ano.

Com os conhecimentos atuais dos índices de produtividade e do valor nutritivo do leite de búfala, é evidente a existência de uma pecuária alternativa, tornando o leite de búfala valioso para o consumo in natura e na elaboração de derivados.

A utilização do leite na preparação de derivados tem sido muito pesquisada, em diferentes regiões do mundo (LAXMINARAYANA \& DASTUR, 1968), por possuir em sua composição elevados teores de gordura, sólidos totais, proteínas, cálcio e fósforo, conseqüentemente elevando os rendimentos na fabricação de queijos, produtos fermentados (FAO, 1991).
Dentre os produtos elaborados no Brasil, - que mais se destaca é o queijo tipo mozzarella que tem um rendimento de 20-25\% (ROSSI, 1977), em função do seu elevado teor em extrato seco total (NEVES, 1985).

Sabendo-se que a produção leiteira de búfalas tem aumentado, é que se propôs neste trabatho a elaborar o queijo tipo mozzarella e o iogurte com leite de búfala, assim como avaliar seu valor nutricional em comparação com os elaborados com leite de vaca.

\section{MATERIAL E METTODOS}

Elaboração de queijo e iogurte de leite de búfala e de vaca

Como matéria prima utilizou-se o leite de búfala e de vaca integrais, os quais foram submetidos às análises físico-químicas, sendo que as amostras foram retiradas do vasilhame de 
fabricação, após homogeneização completa dos mesmos.

A elaboração dos queijos e iogurtes foi realizada no Laboratório de Nutrição Humana da Escola Superior de Agricultura "Luiz de Queiroz".

\section{Elaboração do queijo tipo mozzarella}

Para a fabricação do queijo foi necessário a adição de algumas substâncias, ou seja, 2,5 gramas de cloreto de cálcio para 10 litros de leite e a proporção de coalho líquido de origem animal foi de 1:10.000. As etapas de fabricação do queijo mozzarella, estão descritas no fluxograma 1 , a metodologia empregada foi a descrita por VALLE (1989).

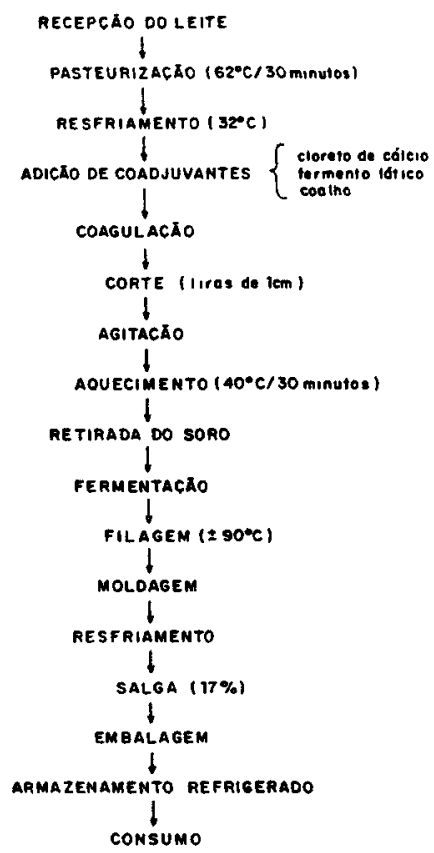

Fluxograma 1 - Elaboração do queijo tipo mozzarella de leite de búfala e de vaca.

\section{Elaboração do iogurte}

A elaboração dos iogurtes com leite de búfala e de vaca integrais foi baseada na metodologia descrita por MORENO (1989). Utilizou-se uma cultura comercial e no final da elaboração adicionou-se ao iogurte $10 \%$ de polpa de frutas em relação ao volume final.

As etapas da fabricação do iogurte estão descritas no fluxograma 2.

Sci. agric., Piracicaba, 50(3):438-443, out./dez., 1993

\section{Análises químicas}

Foram realizadas análises bromatológicas nos queijos e iogurtes, de acordo com a metodologia descrita em ASSOCIATION OF OFFICIAL ANALYTICAL CHMISTS (1990) para gordura, proteína bruta, cinzas e umidade.

\section{Extrato seco total}

Os queijos e iogurtes foram submetidos à determinação do extrato seco total, utilizando metodologia descrita por FURTADO (1975).

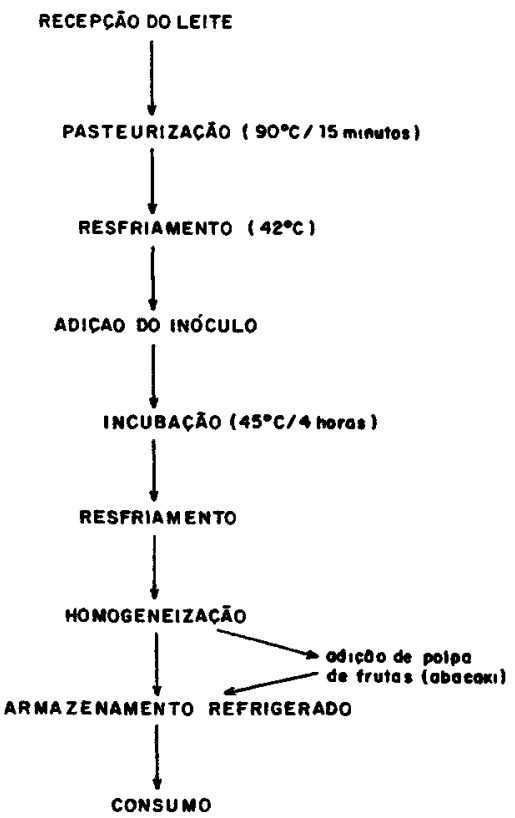

Fluxograma 2 - Elaboração do iogurte de leite de búfala e de vaca.

\section{Análise de minerais}

As amostras dos queijos e iogurtes foram analisadas quanto aos níveis de minerais, em extratos obtidos mediante a digestão nitroperclórica e leitura em espectrofotômetro de absorção atômica conforme método descrito por SARRUGE \& HAAG (1979). 


\section{Digestibilidade in vitro}

As amostras de queijos e iogurtes foram submetidas à análise de proteína (AOAC, 1990) e em seguida foi feita a análise de digestibilidade in vitro, conforme metodologia descrita por AKESON \& STAHMANN (1964). Este método baseia-se na hidrólise enzimática das proteínas da amostra com pepsina e pancreatina, seguida da determinação da proteína digerida com ácido tricloroacético.

\section{RESULTADOS E DISCUSSÃO}

\section{Queijo tipo mozzarella}

A composição química e nutricional do queijo tipo mozzarella elaborado com ambos os leites está disposta na TABELA 1.

O queijo tipo mozzarella elaborado com leite de búfala apresentou uma superfície branca, enquanto que o elaborado com leite de vaca mostrou-se uma coloração amarelada, devido à presença do B-caroteno no leite de vaca.

Para os teores de umidade, o queijo tipo mozzarella elaborado com leite de búfala apresentou valores inferiores ao de vaca, estando de acordo com os dados obtidos por ROSSI (1977) e BONASSI et al. (1982). Segundo CASTALDO (1960), a típica mozzarella de búfala da Itália possui umidade em torno de $57 \%$ e $54 \%$ de gordura no extrato seco.

Para os valores de umidade do queijo tipo mozzarella feito com leite de vaca, os dados estão semelhantes aos de ROSSI (1977); SCHIFFAN \& KOMATSU (1979); FOX \& GUINEE (1987) e FURTADO (1991).

Quanto aos teores de proteína, o queijo preparado com leite de búfala integral apresentou teores maiores, estando os resultados, tanto para o queijo mozzarella de búfala, como para o de vaca de acordo com ROSSI (1977).

A gordura e os sólidos totais obtidos nas análises para o queijo mozzarella de búfala foram superiores ao de vaca, concordando com os resultados citados por ROSSI (1977) para ambos os queijos. SCHIFFAN \& KOMATSU (1979) também obtiveram dados semelhantes para o queijo de leite de vaca.

Os teores de cinzas foram superiores, tanto para o queijo de leite de búfala como de vaca. Os resultados estão de acordo com os citados por BONASSI et al. (1982).
LAXMINARAYANA \& DASTUR (1968), relataram que o elevado teor de cinzas no queijo feito com o leite de búfala está relacionado com o elevado teor de cálcio presente no leite.

Para os níveis de digestibilidade in vitro o queijo tipo mozzarella de leite de búfala mostrou dados levemente superiores ao de vaca, indicando que ambos possuem alta digestibilidade, devido ao elevado teor de proteína e a presença de aminoácidos de alto valor biológico (KRAUSE \& MAHAN, 1991).

Quanto aos teores de minerais nos queijos, os resultados estão apresentados na TABELA 2.

O teores de cálcio e fósforo estão em quantidades maiores no queijo tipo mozzarella de leite de búfala, do que no queijo de leite de vaca.

Para os demais minerais o queijo mozzarella de leite de búfala superou o queijo de leite de vaca nos teores de ferro e zinco; para o magnésio e potássio os dados foram semelhantes.

\section{Iogurte}

Os resultados da composição das análises química e nutricional dos iogurtes estão dispostos na TABELA 3. Os valores para umidade do iogurte de leite de vaca foram superiores ao de búfala integral.

Os valores de proteína foram mais elevados para o iogurte de leite de búfala devido principalmente ao alto conteúdo protéico do leite de búfala. Os valores de proteína do iogurte feito de leite de vaca integral estão de acordo com FERREIRA \& CHAVES (1981).

Para os teores de gordura, bem como para os sólidos totais e cinzas, o iogurte elaborado com leite de búfala apresentou valores superiores em relação ao elaborado com leite de vaca, o que está relacionado com a composição química inicial do leite.

Segundo GANGULI (1979) o iogurte de leite de búfala integral possui a consistência melhor do que o preparado com leite de vaca, o que é justificado pelo elevado teor de sólidos totais, no leite de búfala.

YABU et al.(1988), relataram que na elaboração do iogurte de leite de vaca, sempre é adicionado leite em pó, tendo como objetivo aumentar os sólidos totais para melhorar a consistência e textura do iogurte. Esse procedimento na elaboração de iogurte com leite de búfala não é necessário, uma vez que o leite possui elevado teor de sólidos. 
TABELA 1 - Avaliação química e nutricional do queijo tipo mozzarella.

\begin{tabular}{lcc}
\hline \hline \multirow{2}{*}{ Parâmetros } & \multicolumn{2}{c}{ Mozzarella } \\
\cline { 2 - 3 } determinados (\%) & Búfala & Vaca \\
\hline Umidade & 48,00 & 53,00 \\
Proteína & 43,20 & 34,00 \\
Gordura & 44,10 & 38,50 \\
Cinzas & 4,64 & 3,77 \\
Extrato seco total & 52,00 & 47,00 \\
Digestibilidade in vitro & 93,70 & 91,70 \\
\hline \hline
\end{tabular}

\% em relação ao extrato seco.

TABELA 2 - Composição mineral do queijo tipo mozzarella.

\begin{tabular}{lcc}
\hline \hline & \multicolumn{2}{c}{ Queijo Mozzarella } \\
\cline { 2 - 3 } Minerais & Búfala & Vaca \\
\hline Cálcio (\%) & 2,35 & 2,10 \\
Fósforo (\%) & 1,43 & 1,05 \\
Potássio (\%) & 0,80 & 0,80 \\
Magnésio (\%) & 0,06 & 0,06 \\
Ferro (ppm) & 125 & 53 \\
Manganês (ppm) & traços & traços \\
Zinco (ppm) & 140 & 103 \\
\hline \hline
\end{tabular}

TABELA 3 - Avaliação química e nutricional do iogurte.

\begin{tabular}{lcc}
\hline \hline \multirow{2}{*}{ Parâmetros } & \multicolumn{2}{c}{ Leites } \\
\cline { 2 - 3 } determinados $(\%)$ & Búfala & Vaca \\
\hline Umidade & 81,10 & 86,50 \\
Proteína & 4,50 & 3,80 \\
Gordura & 7,10 & 3,80 \\
Extrato seco total & 18,90 & 13,50 \\
Cinza & 0,76 & 0,73 \\
Digestibilidade in vitro & 93,50 & 91,50 \\
\hline \hline
\end{tabular}


TABELA 4 - Composição mineral do iogurte de leite de búfala e de vaca.

\begin{tabular}{lcc}
\hline & \multicolumn{2}{c}{ logurte } \\
\cline { 2 - 3 } Minerais & Búfala & Vaca \\
\hline Cálcio (\%) & 1,44 & 1,29 \\
Fósforo (\%) & 0,93 & 0,92 \\
Potássio (\%) & 0,90 & 0,90 \\
Magnésio (\%) & 0,09 & 0,09 \\
Ferro (ppm) & 26 & 33 \\
Manganês (ppm) & 11 & 12 \\
Zinco (ppm) & 59 & 64 \\
\hline \hline
\end{tabular}

Para a digestibilidade in vitro dos iogurtes, o elaborado com leite de búfala apresentou valores levemente superiores em relação ao de vaca.

Segundo DEETH \& TAMINE (1981) o iogurte é excelente fonte de aminoácidos e é regulador das funções digestivas, sendo mais digestivo que o leite, pois a acidez característica do produto estimula as enzimas digestivas, facilitando a digestão gástrica.

Os teores de minerais presentes nos iogurtes estão dispostos na TABELA 4.

Para os níveis de cálcio, fósforo, potássio, magnésio e manganês, os valores foram semelhantes e para os minerais ferro e zinco, o iogurte elaborado com leite de vaca apresentou valores superiores aos elaborado com leite de búfala.

\section{CONCLUSÕES}

- O queijo tipo mozzarella e o iogurte, elaborados com leite de búfala, apresentaram níveis superiores em proteína, gordura, cinzas, cálcio e fósforo, estando relacionados com a composição química inicial do leite;

- Os níveis de digestibilidade in vitro do queijo tipo mozzarella e iogurte de leite de búfala, apresentaram resultados semelhantes de leite de vaca, mostrando-se altamente satisfatórios para o consumo humano.

\section{REFERÊNCIAS BIBLIOGRÁFICAS}

AKESON, W.R.; STAHMANN, M.S. A pepsin pancreatin digest index of protein quality evaluation. Journal of Nutrition, Bethesda, v.83, n.3, p.257-261, 1964.

ASSOCIATION OF OFFICIAL ANALYTICAL CHEMISTS. Official methods of analysis. 15.ed. Washington, 1990. 2v.

BONASSI, I.A.; CARVALHO, J.B.C.; VILLARES, J.B. Utilização do leite de búfala como matéria-prima para elaboração do queijo mozzarella. Archivos Latinoamericanos de Nutricion,. Guatemala, v.32, n.4, p.903-912, Dec. 1982.

CASTALDO, M.C. La búfala es il suo tipico prodotto "la mozzarella". Rivista di Zootecnia, Milan, v.32, n.7/8, p.203-208, 1960.

DEETH, H.C.; TAMINE, A.Y. Yogurt: nutritive and therapeutic aspects. Journal of Food Protection, Ames, v.44, n.1, p.78-86, 1981.

FAO. O búfalo. Brasilia: Ministério da Agricultura; São Paulo: Associação Brasileira dos Criadores de Búfalos, 1991. 320p. (FAO. Produção animal e saúde, 4).

FERREIRA, C.L.L.F.; CHAVES, J.B.P. Caracterização do iogurte comercializado na Zona da Mata, Minas Gerais. Revista do Instituto de Laticínios Cândido Tostes, Juiz de Fora, v.36, n.218, p.27-31, 1981.

FOX, P.F.; GUINEE, T.P. Italian cheeses. In: FOX, P.F. Cheese: chemistry, physics and microbiology. 
New York: Elsevier Applied Science, 1987. v.2, p.221-255.

FURTADO, J.P. Análises bromatologicas. Juiz de Fora, Universidade Federal de Juiz de Fora, 1975. 79p.

FURTADO, M.M. A arte e a ciência do queijo. São Paulo, Globo, 1991. 297p.

GANGULI, N.C. Tecnologia de la leche de búfala Revista Mundial de Zootecnia, Roma, v.30, p.2-10, 1979.

KRAUSE, M.V.; MAHAN, L.K. Alimentos, nutrição e dietoterapia. 7.ed., São Paulo: Roca, 1991. 981 p.

LAXMINARAYANA, H. \& DASTUR, N.N. Buffaloes' milk and milk products. I. Dairy Science Abstracts, Wallingford, v.30, n.4, p.177-186, 1968.

MORENO, I. Iogurte. In: VAN DENDER, A.G.F. Utilização artesanal do leite de búfala. Campinas, ITAL, 1989. p.25-33, (ITAL. Manual técnico, 3).

NEVES, N.L.B. Contribuição da bubalinocultura para a produção leiteira. In: PEDXOTO, A.M.; MOURA, J.C. de; FARIA, V.P. de. Caracterização e implementação de uma politica para o leite. Piracicaba: FEALQ, 1985. p.37-45.
ROSSI, G. Manuali di tecnologia casearia. Bologna: Agricole, 1977. 684p.

SARRUGE, J.R.; HAAG, H.P. Análises químicas em plantas. Piracicaba: ESALQ, 1979. 40p.

SCHIFFAN, T.Z.; KOMATSU, I. Estudo sobre a composição do queijo mozzarella consumido na cidade de São Paulo. Revista do Instituto de Laticínios Cândido Tostes, Juiz de Fora, v.34, n.205, p.29-34, 1979.

VALLE, J.L.E. Queijos de massa filada. In: VAN DENDER, A.G.F. Utilização artesanal do leite de búfala. Campinas: ITAL, 1989. p.57-60, (ITAL. Manual técnico, 3).

YABU, M.C.; SCHOLZ, M.B.S.; RAPACCI, M.; ANTUNES, L.A.F. Características físico-químicas e sensoriais de iogurte produzido de misturas de leite bovino e bubalino. Revista do Instituto de Laticínios Cândido Tostes, Juiz de Fora, v.43, n.258, p.35-37, 1988.

Enviado para publicação em 28.07.93

Aceito para publicação em 28.09.93 